05

\title{
Исследование динамических свойств водонасыщенного песка по результатам обращенных экспериментов
}

\author{
() А.М. Брагов, Вл.В. Баландин, В.Л. Котов, Вл.Вл. Баландин \\ Научно-исследовательский институт механики \\ Национального исследовательского Нижегородского государственного университета им. Н.И. Лобачевского, \\ 603950 Нижний Новгород, Россия \\ e-mail: bragov@mech.unn.ru
}

(Поступило в Редакцию 3 июля 2017 г.)

\begin{abstract}
Приведены новые экспериментальные результаты по исследованию динамических свойств песчаного грунта на основе методики обращенного эксперимента с применением мерного стержня с плоским передним торцом. Показана ограниченная применимость методики с использованием процедуры коррекции формы импульса деформации за счет дисперсии при его распространении в мерном стержне. Получены оценки максимума импульса, приведены результаты сравнения численных расчетов с экспериментальными данными, показана достаточная точность определения значения силы сопротивления внедрению на квазистационарной стадии. В ходе экспериментально-расчетного анализа максимальных значений силы сопротивления и ее значений на квазистационарной стадии внедрения определены параметры динамической сжимаемости и сопротивления сдвигу водонасыщенного песка. Установлено, что при практически полном водонасыщении песка его сдвиговые свойства снижаются, но остаются сушественными в практически важном диапазоне скоростей внедрения.
\end{abstract}

DOI: $10.21883 /$ JTF.2018.04.45722.2412

\section{Введение}

Систематическое изучение физико-механических характеристик мягких грунтов при динамическом нагружении началось достаточно давно. Ставшие классическими экспериментальные методы $[1,2]$ на основе предложенных модельных представлений [3-5] о динамической сжимаемости и сопротивлении сдвигу грунтовых сред получили широкое распространение и продолжают развиваться [6]. Разработанные методики плосковолнового эксперимента позволяют определять ударную адиабату сухого и влажного песка $[1,7-9]$ в диапазоне нагрузок до нескольких гигапаскалей. Для получения сведений о прочностных свойствах мягких грунтов наряду с осевой компонентой тензора напряжений необходимо одновременно измерять и радиальную компоненту в образце грунта, что сопряжено со значительными техническими и методическими трудностями. Сдвиговые свойства экспериментально определяются с применением различных модификаций [10-13] методики Кольского при существенно меньших давлениях. Хорошо зарекомендовал себя подход к изучению проблемы высокоскоростной деформации мягких грунтовых сред, сочетающий в себе современные методы динамических испытаний [14,15]: модифицированную методику Кольского и систему разрезных стержней Гопкинсона с образцами среды, заключенными в обоймы, и методику плосковолновых ударных экспериментов.

Динамические характеристики грунтовых сред зависят от многих факторов, таких, как начальная пористость, компонентный и фракционный состав, влажность. Так, например, известно, что уплотнение сухого песчаного грунта ведет к изменению его проч- ностных характеристик, что приводит к существенному изменению глубин проникания ударников [16]. При подготовке образцов в работах [7-15] плотность насыпного песка составляла $1300-1600 \mathrm{~kg} / \mathrm{m}^{3}$.Влияние предварительного уплотнения сухого песка на ударную сжимаемость исследовалось в работах $[11,12]$, где начальная плотность достигала $1620 \mathrm{~kg} / \mathrm{m}^{3}$. Исключение составляют плосковолновые эксперименты [13], где средняя плотность сухого песка составляла $1730 \mathrm{~kg} / \mathrm{m}^{3}$, однако ударные адиабаты были построены по двум точкам в диапазоне давлений $1-10 \mathrm{GPa}$. Таким образом, достоверные экспериментальные результаты по непосредственному определению динамических характеристик уплотненного грунта практически отсутствуют.

Ранее был предложен экспериментально-расчетный метод определения динамической сжимаемости и сдвиговой прочности грунта на основе сочетания физического и численного моделирования процессов удара и проникания [17]. Методика обращенного ударного эксперимента с использованием мерного стержня с плоским торцом [18] позволяет определять ударную сжимаемость сухого песка повышенной плотности $1700-1850 \mathrm{~kg} / \mathrm{m}^{3}$ [19]. В работе [20] показано, что сдвиговые характеристики грунтовых сред коррелируют со значениями силы сопротивления на квазистационарной стадии внедрения $[21,22]$. В настоящей работе развивается подход, предложенный в [18-22], и представлены новые экспериментальные результаты по исследованию динамической сжимаемости и сопротивлению сдвигу уплотненного водонасыщенного грунта, что имеет важное значение при решении прикладных задач проникания твердых тел в грунтовые среды. 


\section{1. Особенности динамических испытаний водонасыщенного грунта в обращенной постановке}

Простая и эффективная методика определения ударной сжимаемости мягких грунтов в обращенном эксперименте изложена в работе [19]. Эта методика позволяет определять динамическую сжимаемость мягких грунтов в диапазоне давлений, который трудно исследовать модифицированным методом Кольского [10] и методом плосковолновых ударных экспериментов [8].

Суть методики [19] для определения ударной сжимаемости мягких грунтов сводится к следующему. Контейнер, заполненный грунтом с плотностью $\rho_{0}$, разгоняется до нужных скоростей и наносит удар по плоскому торцу мерного стержня, в котором формируется упругий импульс деформаций $e(t)$. Регистрация этого импульса тензодатчиками, наклеенными на поверхности мерного стержня, позволяет определить усилие $F$, действующее на ударник при взаимодействии со средой, по известному соотношению $F(t)=E e(t) S_{0}$, где $E-$ модуль упругости стержня, $S_{0}$ - площадь поперечного сечения. Из соотношений Гюгонио на контактной границе стержень-грунт определяется скорость ударной волны $D$ в зависимости от массовой скорости $u$ : $D(u)=$ $=F /\left(\rho_{0} u S_{0}\right), \quad u=V_{0-} F /\left(\rho c_{0} S_{0}\right), \quad$ где $c_{0}-$ скорость распространения продольной волны в стержне, $\rho$ плотность материала стержня.

Динамическая сжимаемость грунта, как и ряда других сжимаемых материалов, описывается ударной адиабатой, которая может быть представлена в виде линейной зависимости

$$
D=A+b u \text {. }
$$

Константа $A$ близка к скорости распространения плоской волны сжатия в грунте при малых давлениях, $b$ характеризует предельную сжимаемость грунта [1].

Известно [4,5], что скорость распространения плоской волны в грунте растет с увеличением водонасыщения, растет также и скорость волны разгрузки. Следствием этого при прочих равных условиях является меньшая длительность импульса сжатия, возбуждаемого в мерном стержне при ударе по нему контейнером с водонасыщенным песком, по сравнению с сухим грунтом [23,24]. При этом нарушается условие, при котором импульс не диспергирует. Таким образом, в случае водонасыщенных грунтов определение усилия, действующего на ударник по значениям импульса деформации, регистрируемого на достаточно большом удалении от плоскости соударения на поверхности мерного стержня, наталкивается на известную проблему, связанную с искажением формы и амплитуды импульса за счет дисперсии при распространении его в мерном стержне, отмеченную еще Г. Кольским [25], Р. Дейвисом [26] и другими авторами [27-33].

\section{1. Условия проведения обращенных экспериментов}

Эксперименты проводились с песчаной смесью естественного состава, из которой были удалены частицы крупнее $1 \mathrm{~mm}$ и менее $0.1 \mathrm{~mm}$. Метаемые контейнеры заполнялись сухим песком, который затем слегка уплотнялся. Контейнеры взвешивались для определения плотности сухого песка, а затем постепенно заливались определенным количеством воды до полного насыщения песка. Контейнеры повторно взвешивались для определения плотности водонасыщенного песка и его влажности относительно его начальной плотности. Средняя плотность исходного сухого песка и водонасыщенной естественной смеси составляла соответственно 1750 и $2090 \mathrm{~kg} / \mathrm{m}^{3}$. Песок в основном состоит из частиц кварца, плотность которого $2650 \mathrm{~kg} / \mathrm{m}^{3}$, таким образом, пористость песка составляет 0.34. При полном заполнении этих пустот водой плотность влажного песка должна возрасти на величину $340 \mathrm{~kg} / \mathrm{m}^{3}$, и плотность водонасыщенного песка должна быть равна $2090 \mathrm{~kg} / \mathrm{m}^{3}$, что практически имело место при проведении экспериментов.

Стальной мерный стержень имел диаметр $d=2 a=$ $=0.0205 \mathrm{~m}$ и длину $1.5 \mathrm{~m}$; плотность материала стержня была равна $\rho=8050 \mathrm{~kg} / \mathrm{m}^{3}$, модуль Юнга $E=186 \mathrm{GPa}$, предел текучести $2 \mathrm{GPa}$, скорость распространения волны в стержне $c_{0}=\sqrt{E / \rho}=4807 \mathrm{~m} / \mathrm{s}$.

На рис. 1 представлены зависимости силы сопротивления внедрению от времени ударника с плоским передним торцом в сухой (кривые 1,2 ) и водонасыщенный (кривые 3,4$)$ песчаный грунт при близких скоростях удара $(182$ и $192 \mathrm{~m} / \mathrm{s}$ соответственно), полученные в численных расчетах $(a)$ и в обращенных экспериментах $(b)$.

Результаты численных расчетов [24] на рис. 1, $a$ представляют значения силы сопротивления в сечении мерного стержня на расстоянии 0 и $0.96 \mathrm{~m}$ от его торца, данные экспериментов на рис. $1, b$ соответствуют показаниям тензорезисторов на поверхности мерного стержня на расстоянии 0.46 и $0.96 \mathrm{~m}$ от ударяемого торца. Временны́е зависимости смещены по оси времени для удобства представления.

Отметим влияние геометрической дисперсии при распространении импульса деформации в мерном стержне, которое проявляется в уменьшении амплитуды и крутизны фронта импульса, увеличении его длительности, появлению колебаний на заднем фронте.

\section{2. Определение квазистационарного значения силы сопротивления}

Далее проводится экспериментально-расчетное определение квазистационарного значения силы сопротивления внедрению в водонасыщенный песок ударника с плоским торцом с учетом дисперсионных эффектов. В работах [32-37] предложены поправки на дисперсию для коррекции формы импульса, основанные на точном решении Похгаммера-Кри для бесконечного упругого 

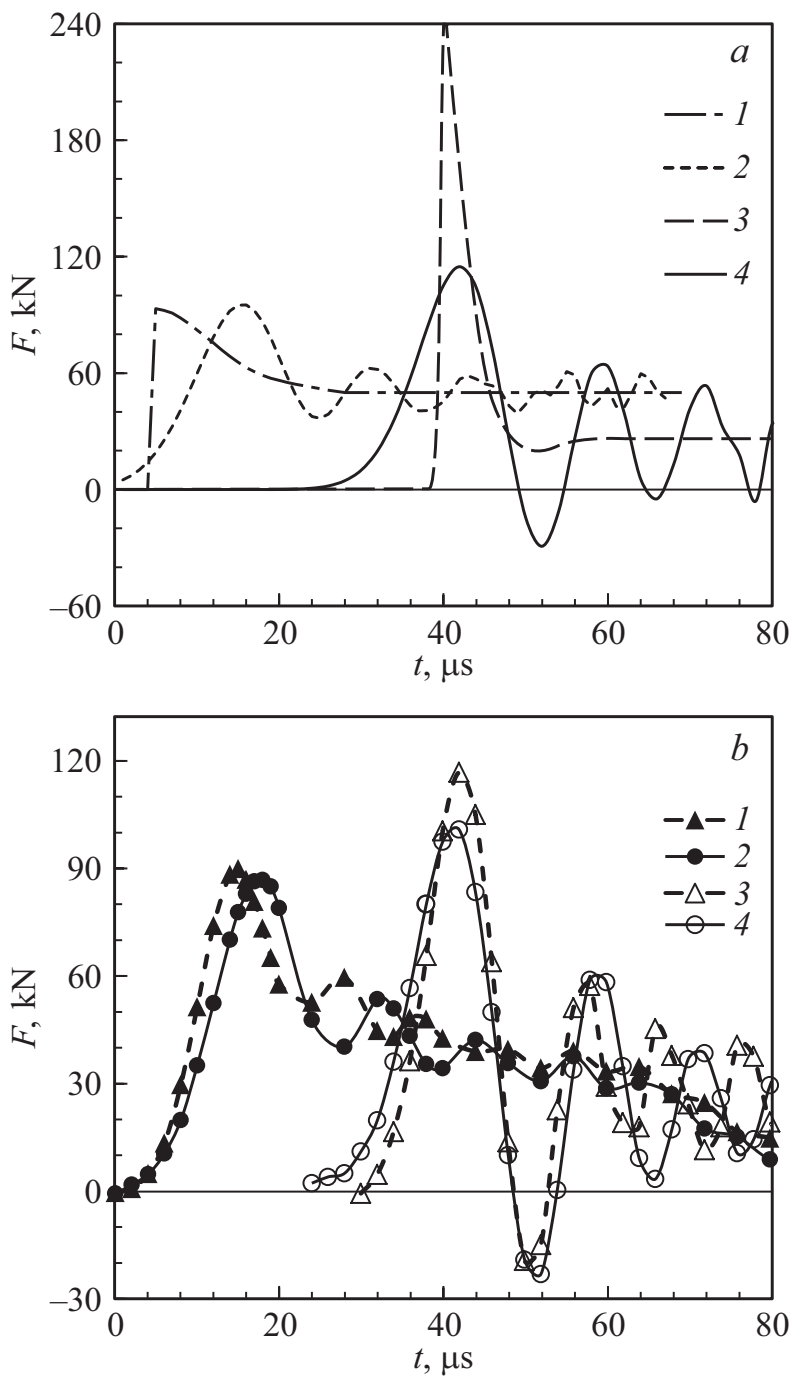

Рис. 1. Зависимости силы сопротивления внедрению от времени, полученные в численных расчетах $(a)$ и в обращенных экспериментах $(b)$ при скоростях внедрения 182 и $192 \mathrm{~m} / \mathrm{s}$ соответственно в сухой и водонасыщенный грунт.

цилиндра и применении преобразования Фурье. В эксперименте импульс деформаций на поверхности мерного стержня с достаточной точностью можно представить в дискретном виде набором точек $e_{n}=e\left(t_{n}\right), t_{n}=n \Delta t$, $n=\overline{0, N-1}$, где $\Delta t-$ шаг дискретизации. Влияние дисперсии при распространении импульса на расстояние $z_{0}$ от торца стержня приводит [32] к сдвигу по частоте на величину $\Delta \varphi$ в каждой гармонике ряда Фурье

$$
\begin{gathered}
\tilde{e}_{n}=\sum_{k=0}^{N / 2} C_{k} \cos \frac{2 \pi k\left(n+\tilde{\varphi}_{k}\right)}{N}, \\
\tilde{\varphi}_{k}=\varphi_{k}+\Delta \varphi_{k}, \quad \Delta \varphi_{k}=\omega_{k} z_{0}\left(\frac{1}{c_{0}}-\frac{1}{c\left(\omega_{k}\right)}\right), \\
\omega_{k}=\frac{2 \pi k(N-1)}{N \Delta t},
\end{gathered}
$$

где $C_{k}$ и $\varphi_{k}, k=0, \ldots, N / 2$ - амплитуды и фазы гармоник ряда Фурье. Зависимость фазовой скорости от частоты $c(\omega)$ определяется из решения дисперсионного уравнения.

Известны модификации методики восстановления импульса, основанные на точном решении Р. Дейвиса задачи о распространении продольной гармонической волны в упругом круговом цилиндре с учетом неравномерности распределения деформаций вдоль поперечного сечения $[34,36]$. В этом случае корректируются также коэффициенты разложения $C_{k}$ :

$$
\begin{gathered}
\tilde{F}=S_{0} \sum_{k=0}^{N / 2} M_{2} \tilde{C}_{k} \cos \frac{2 \pi k\left(n+\tilde{\varphi}_{k}\right)}{N}, \\
\tilde{C}_{k}=M_{1} C_{k}, \quad M_{1}=\frac{2\left(1+\frac{1-S Z}{Z-1}\right)}{\frac{\eta a J_{0}(\eta a)}{J_{t}(\eta a)}+\frac{(1-S Z)}{(Z-1)} \frac{\chi a J_{0}(\chi a)}{J_{1}(\chi a)}}, \\
S=\frac{1-2 v}{1-v}, \\
Z=(1+v)\left(\frac{c(\omega)}{c_{0}}\right)^{2}, \quad \eta=s \sqrt{S Z-1}, \quad \chi=s \sqrt{2 Z-1}, \\
M_{2}=E\left(\frac{c(\omega)}{c_{0}}\right)^{2}, \quad c_{0}=\sqrt{E / \rho}
\end{gathered}
$$

где $v-$ коэффициент Пуассона, $J_{0}, J_{1}-$ функции Бесселя, $s$ - волновое число. Умножение каждой гармоники ряда Фурье на множитель $M_{1}$ преобразует деформацию на поверхности мерного стержня в среднюю по поперечному сечению деформацию, введение множителя $M_{2}$ позволяет рассчитать среднее напряжение [37].

Для верификации применяемой методики коррекции формы импульса ранее проводилось [24,38] численное моделирование динамического процесса формирования ударного импульса на основе модифицированного метода Годунова и распространения его в мерном стержне в рамках схемы „крест“ с учетом осевой симметрии в постановке, соответствующей обращенному эксперименту.

Рассмотрим один из результатов обращенного эксперимента, в котором контейнер с водонасыщенным грунтом наносит удар со скоростью $V_{0}=320 \mathrm{~m} / \mathrm{s}$ по плоскому торцу мерного стержня. Напряжения на поверхностях контакта стержня и грунта в момент удара равны, что с учетом (1) позволяет получить уравнение для определения массовой скорости $u$, соответствующей скорости удара $V_{0}: \rho c\left(V_{0}-u\right)=\rho_{0}(A+b u) u$, где $c$ - скорость распространения продольной волны в полупространстве $(c=5600 \mathrm{~m} / \mathrm{s})$. Решая уравнение, получаем скорость $u=283 \mathrm{~m} / \mathrm{s}$, максимальное напряжение $1.4 \mathrm{GPa}$. Соответствующее максимальное значение силы, действующей на передний торец стержня, составляет $450 \mathrm{kN}$ [38].

На рис. 2 представлены силы сопротивления внедрению ударника в водонасыщенный грунт со скоростью $320 \mathrm{~m} / \mathrm{s}$. Кривая 1 соответствует усилию $F=$ 


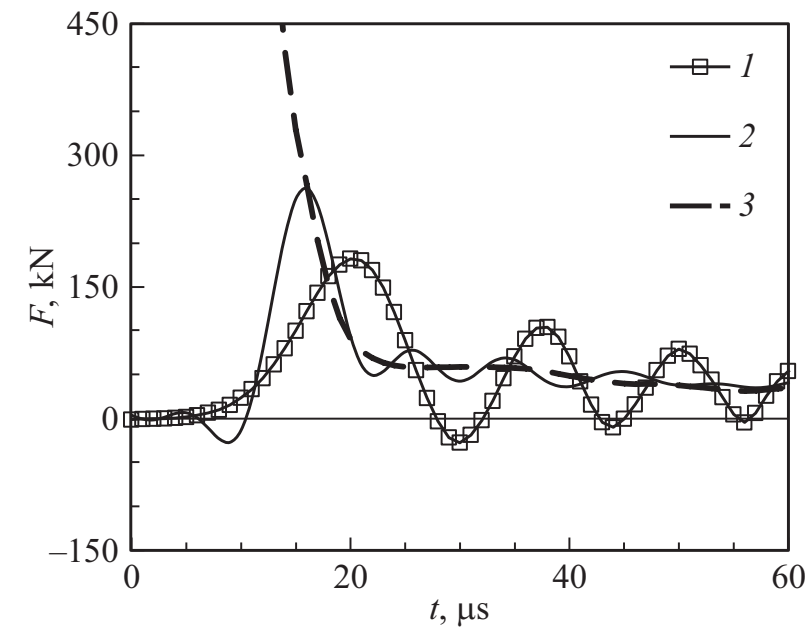

Рис. 2. Импульсы силы, соответствующие деформации на поверхности мерного стержня, полученные в обращенном эксперименте (кривые 1 и 2) и численном расчете [38] (кривая 3).

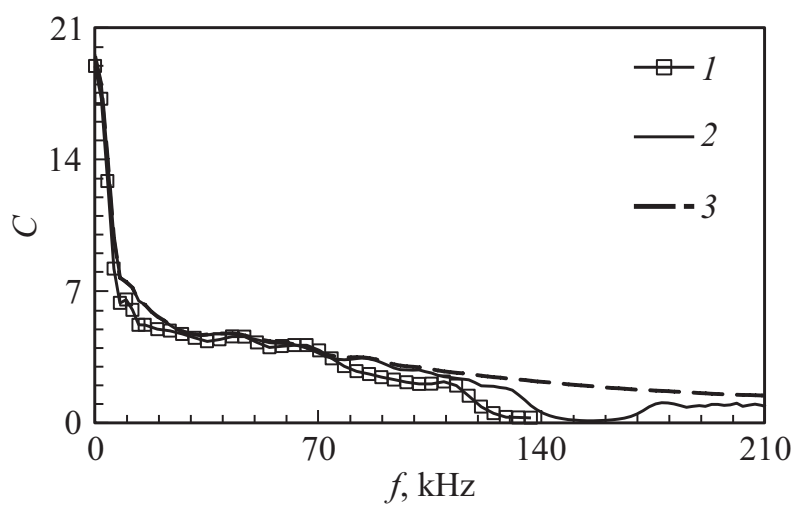

Рис. 3. Амплитудный спектр импульсов в мерном стержне.

$=E e(t) S_{0}$, где импульс деформации $e(t)$ зарегистрирован на поверхности мерного стержня на расстоянии 0.96 m от его торца; кривая 2 представляет экспериментальные данные с поправкой на дисперсию с учетом неравномерности распределения деформации по поперечному сечению стержня по формулам (2); кривая 3 представляет результаты численных расчетов [38]. Для удобства представления импульсы смещены по оси времени к началу координат.

Отметим существенное отличие максимальных значений, полученных в расчете и в эксперименте, и близость результатов на квазистационарной стадии внедрения.

На рис. 3 представлено спектральное разложение импульса деформации, распространяющегося по стержню $(f=\omega /(2 \pi))$. Кривые 1 и 2 соответствуют результатам эксперимента и численного расчета на расстоянии $0.96 \mathrm{~m}$ от торца стержня, кривая 3 представляет спектр расчетного импульса на торце стержня (показан кривой 3 на рис. 2). Отметим, что при частоте более $f_{k} \approx 140 \mathrm{kHz}$ амплитуда импульса, распространяющего- ся в стержне, обращается в нуль, в то время как амплитуда исходного импульса на торце стержня отлична от нуля.

Данная частота, как отмечалось ранее [24,36-38], является критической для стержня данного радиуса. Для сухого песчаного грунта влияние дисперсии мало, так как спектр импульса сжатия практически не содержит частот, превышающих граничную частоту $140 \mathrm{kHz}$ (для стержня диаметром $20.5 \mathrm{~mm}$ ) [25,26]. В случае водонасыщенного грунта длительность импульса сжатия, возникающего в стержне, значительно меньше, в спектре сигнала появляются компоненты с частотой $140 \mathrm{kHz}$ и выше, которые подвержены сильной дисперсии. Поэтому происходит искажение формы импульса сжатия в стержне и уменьшение его максимального значения [23,24].

Таким образом, применяемая процедура коррекции формы импульса не позволяет определить максимум столь короткого импульса, однако значение силы сопротивления на квазистационарной стадии внедрения, устанавливающейся после резкого спада, определяется достаточно точно.

\section{3. Оценка максимального значения силы сопротивления}

Примем для зависимости деформации на поверхности мерного стержня от времени следующую аппроксимацию:

$$
e(t)=\left(A_{M}-A_{0}\right) e^{(-\alpha t)}+A_{0}, \quad t \geq 0, \quad \alpha>0 .
$$

Зависимость (3) характеризуется тем, что при $t=0$ деформация $e$ принимает максимальное значение $A_{M}$, а при $t \gg 0$ отличие от постоянного значения $A_{0}$ становится пренебрежимо малым. При соответствующем выборе параметров $A_{M}, A_{0}$ и $\alpha$ зависимость (3) будет аппроксимировать импульс на торце мерного стержня.

При распространении импульса $e(t)$ в упругом мерном стержне при отношении радиуса стержня к длине волны $a / \Lambda>0.1$ он подвержен действию дисперсии во временной области, однако его амплитудный спектр $C(f)$ в частотной области не меняется. Принимая во внимание свойство площади преобразования Фурье $C(0)=\int_{-\infty}^{\infty} e(t) d t$ и теорему Парсеваля $\int_{-\infty}^{\infty}(e(t))^{2} d t=\int_{-\infty}^{\infty}(C(f))^{2} d f$, вычислим площадь и энергию сигнала для аппроксимации $e(t)$ в виде (3) на промежутке времени $[0, \tau]$

$$
\begin{gathered}
\int_{0}^{\tau}\left(\left(A_{M}-A_{0}\right) e^{(-\alpha t)}+A_{0}\right) d t \approx \frac{A_{M}-A_{0}}{\alpha}+A_{0} \tau, \\
\int_{0}^{\tau}\left(\left(A_{M}-A_{0}\right) e^{(-\alpha t)}+A_{0}\right)^{2} d t \approx \frac{1}{2} \frac{A_{M}^{2}+2 A_{M} A_{0}-3 A_{0}^{2}}{\alpha}+A_{0}^{2} \tau .
\end{gathered}
$$




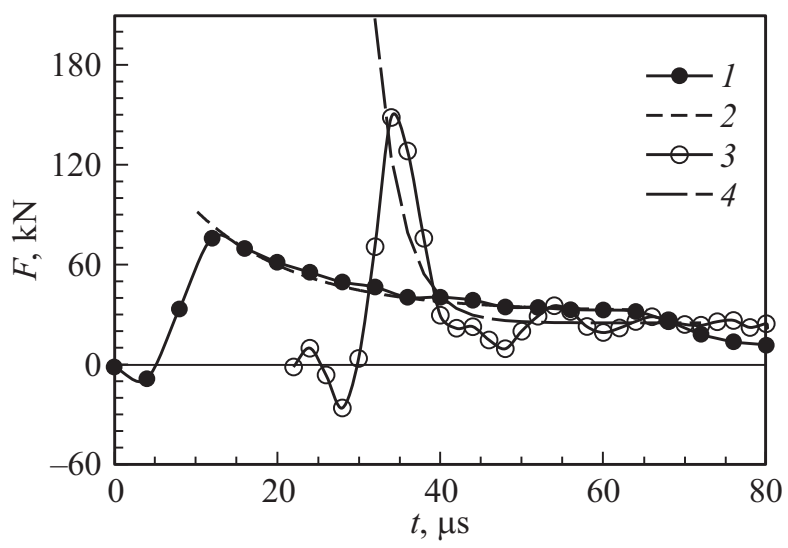

Рис. 4. Восстановленные зависимости силы сопротивления внедрению от времени в сухом и водонасыщенном грунте, полученные при учете поправки на дисперсию (2) и их аппроксимации по формулам (3)-(5).

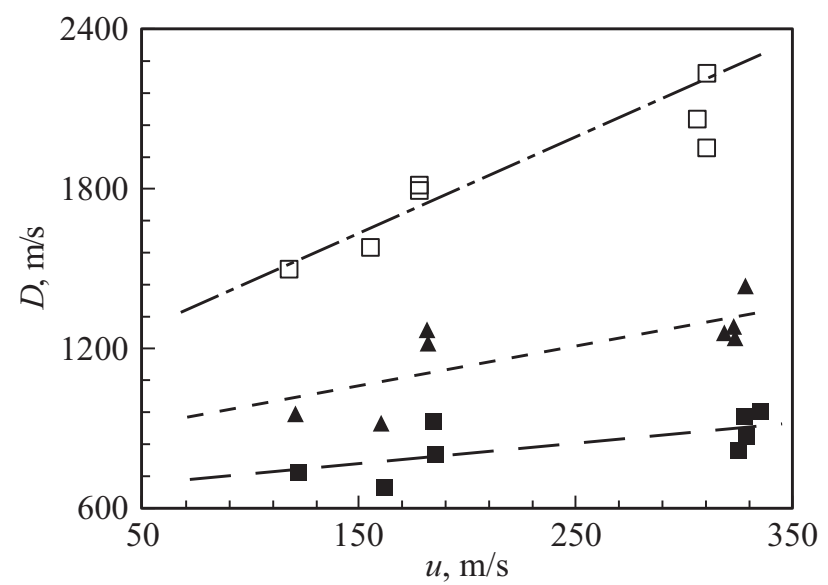

Рис. 5. Ударные адиабаты водонасыщенного грунта, полученные по результатам обращенных экспериментов, с поправкой на дисперсию (2), экспоненциальная оценка снизу по формулам (3)-(5).

Величина промежутка $\tau$ соответствует времени установления квазистационарного значения $A_{0}$ в обращенном эксперименте. Приближенные равенства становятся точными при $\tau=\infty$, однако при величине $\tau \approx 50 \mu \mathrm{s}$, наблюдаемой в экспериментах, погрешность вычислений по формулам (4) не превышала $1 \%$. Левые части равенств (4) вычисляем на основе экспериментальных данных $e_{n}=e\left(t_{n}\right)$ на промежутке времени $[0, \tau]: S=\sum_{n=0}^{l} e_{n}$, $I=\sum_{n=0}^{l}\left(e_{n}\right)^{2}, t_{l}<\tau<t_{l+1}$.

Таким образом, при известных $A_{0}$ и $\tau$ для определения параметров $A_{M}$ и $\alpha$ имеем систему двух уравнений

$$
\begin{gathered}
\frac{A_{M}-A_{0}}{\alpha}=S-A_{0} \tau, \\
\frac{A_{M}^{2}+2 A_{M} A_{0}-3 A_{0}^{2}}{\alpha}=2\left(I-A_{0}^{2} \tau\right) .
\end{gathered}
$$

Как было отмечено в разд. 1.2, при достижении критической частоты $f_{k} \approx 140 \mathrm{kHz}$ амплитуда $C\left(f_{k}\right)$ обращается в нуль (см. также рис. 3), в то время как амплитуда искомого импульса отлична от нуля. В силу теоремы Парсеваля полученные на основе интеграла в (4) значения параметров аппроксимации (3) дадут оценку снизу для максимального значения импульса деформации в стержне.

На рис. 4 приведены зависимости силы сопротивления внедрению от времени в сухом и водонасыщенном грунтах, определенные по значениям импульсов деформации на поверхности мерного стержня, измеренным на расстоянии $0.96 \mathrm{~m}$ от ударяемого торца при учете поправок на дисперсию по формулам (2) и их аппроксимации по формулам (3).

Исходные импульсы, полученные в обращенном эксперименте, приведены на рис. 2.

Отметим, что в случае сухого песчаного грунта применение процедуры коррекции по формулам (3)-(5) практически не сказывается на максимальном значении импульса, экспоненциальная аппроксимация (3) достаточно точно повторяет форму импульса во времени от максимального до квазистационарного значения. Для водонасыщенного грунта поправка на дисперсию приводит к увеличению максимального значения силы в 1.5 раза, оценка оказывается большей еще на $40 \%$.

На рис. 5 приведены $D(u)$ ударные адиабаты водонасыщенного грунта, полученные в ходе обработки данных обращенных экспериментов (темные квадраты), полученные по методике [19] и с учетом поправки на дисперсию по формулам (2) (темные треугольники) и на основе оценки по формулам (3)-(5) (светлые квадраты); прямые линии представляют линейные МНК аппроксимации (1).

\section{2. Идентификация ударной сжимаемости грунта}

Ударная адиабата (1), представленная в виде линейной зависимости $D(u)$ и полученная в плосковолновых экспериментах с помощью соотношений Гюгонио $\sigma=$ $=\rho_{0} D u, \theta=u / D$, может быть преобразована к виду $\sigma(\theta)=\rho_{0} A^{2} \theta /(1-b \theta)^{2}$, где $\theta=1-\rho_{0} / \rho-$ объемная деформация, $\rho_{0}$ и $\rho-$ начальная и текущая плотность грунта, $\sigma(\theta)$ - зависимость напряжения от объемной деформации.

Для проведения расчетов процессов удара и проникания в грунт в широком диапазоне изменения параметров удобной аппроксимацией ударной адиабаты мягких грунтов является модель пористой среды [39-43]

$$
\begin{aligned}
& \frac{\rho_{0}}{\rho}=\sum_{i=1}^{3} \alpha_{i}\left(\frac{\sigma}{B_{i}}+1\right)^{1 / n_{i}}, \\
& B_{i}=\frac{\rho_{i 0} c_{i 0}^{2}}{n_{i}}, \quad i=1,2,3,
\end{aligned}
$$

где $\alpha_{1}, \alpha_{2}, \alpha_{3}$ - объемные концентрации свободной пористости (защемленного воздуха и/или других газов), 
Таблица 1. Параметры ударных адиабат воды [41] и кварца [39]

\begin{tabular}{c|c|c|c|c}
\hline$i$ & $\rho_{i 0}, \mathrm{~kg} / \mathrm{m}^{3}$ & $B_{i}, \mathrm{MPa}$ & $n_{i}$ & $c_{i 0}, \mathrm{~m} / \mathrm{s}$ \\
\hline 2 & 1000 & 304.5 & 7.15 & 1475 \\
3 & 2650 & 9118.7 & 4 & 3710
\end{tabular}

жидкости (воды) и кварца; $\rho_{i 0}$ и $c_{i 0}, i=1,2,3$ - плотности и скорости распространения продольных волн соответствующих в компонентах, $\rho_{0}=\alpha_{1} \rho_{10}+\alpha_{2} \rho_{20}+\alpha_{3} \rho_{30}$, $\alpha_{1}+\alpha_{2}+\alpha_{3}=1$.

Известные значения констант уравнения (6), относящиеся к параметрам ударных адиабат воды и кварца [39-42], приведены в табл. 1.

Величины $\rho_{10}, B_{1}, n_{1}$, соответствующие сжимаемости начальной свободной пористости, не связаны со сжимаемостью газового компонента и определяются для каждого грунта отдельно по результатам экспериментов.

\section{1. Результаты плосковолновых экспериментов}

Известны результаты экспериментов по определению параметров ударной адиабаты фракционированного сухого и водонасыщенного песка [1]. Плотность сухого песка для различных фракций изменялась в диапазоне $1300-1600 \mathrm{~kg} / \mathrm{m}^{3}$, скорости удара принимали значения от 500 до $1900 \mathrm{~m} / \mathrm{s}$. Средняя плотность образцов песка, содержащего 3\% глины, в экспериментах [9] составляла $1730 \mathrm{~kg} / \mathrm{m}^{3}$, скорости удара также превышали $500 \mathrm{~m} / \mathrm{s}$.

Ранее были получены результаты плосковолновых экспериментов [8] с образцами песка с размерами частиц $0.2-0.315 \mathrm{~mm}$ в диапазоне $100-500 \mathrm{~m} / \mathrm{s}$, в котором существенны сдвиговые свойства песчаного грунта. Плотность сухого песка составила $1600 \pm 50 \mathrm{~kg} / \mathrm{m}^{3}$, плотность водонасыщенного песка $-1900 \pm 50 \mathrm{~kg} / \mathrm{m}^{3}$.

Приведем параметры уравнения состояния (6) для сухого и влажного грунтов. Величина плотности свободного пространства задавалась равной плотности воздуха $\rho_{10}=1.300 \mathrm{~kg} / \mathrm{m}^{3}$, а параметры $B_{1}$ и $n_{1}$ подбирались методом наименьших квадратов из условия наилучшего соответствия результатам эксперимента для сухого грунта. При значениях параметров $\alpha_{1}=0.395, \alpha_{2}=0.001$, $\alpha_{3}=0.59$, начальной плотности $\rho_{0}=1565 \mathrm{~kg} / \mathrm{m}^{3}$ и влажности грунта $w=0.1 \%$, значения искомых констант составили $B_{1}=180 \mathrm{MPa}$ и $n_{1}=0.4$. Влажность грунта определялась по формуле $w=\frac{\rho_{0}-\alpha_{3} \rho_{30}}{\alpha_{3} \rho_{30}} \cdot 100 \%$. Для грунта с влажностью $w=19.2 \%$ при значениях параметров $\alpha_{1}=0.11, \alpha_{2}=0.3, \alpha_{3}=0.59$ начальная плотность грунта составила $\rho_{0}=1864 \mathrm{~kg} / \mathrm{m}^{3}$.

На рис. 6 представлены ударные адиабаты песка с размерами частиц $0.2-0.315 \mathrm{~mm}$ : светлые и темные квадраты соответствуют данным плосковолновых экспериментов [8] для сухого и влажного песчаного грунта, штриховая и сплошная линии соответствуют данным,

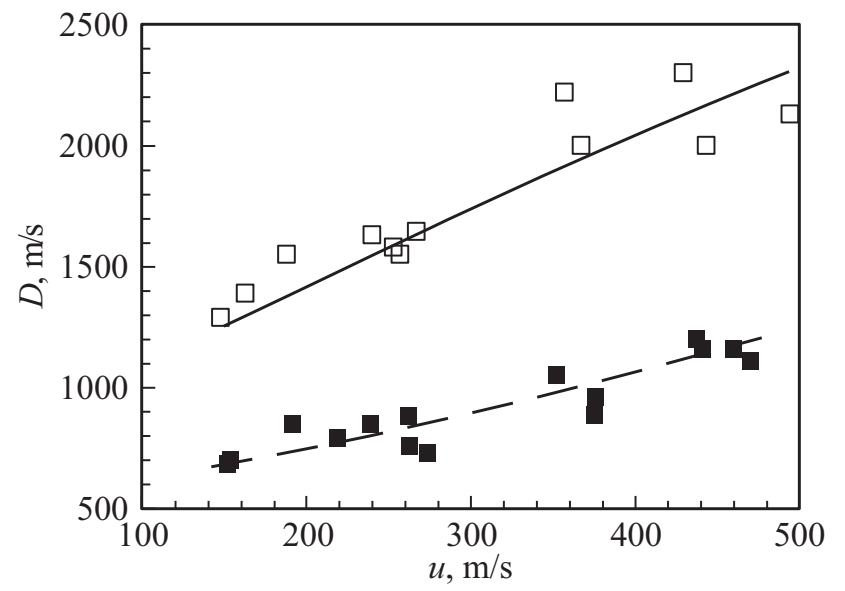

Рис. 6. Ударные адиабаты песка с размерами частиц $0.2-0.315 \mathrm{~mm}$ и влажностью 0.1 и $19.2 \%$, полученные в результате плосковолновых экспериментов [8] и в рамках модели трехкомпонентной среды (6).

полученным по формуле (6) для грунтов с влажностью $w=0.1$ и $19.2 \%$. Отметим хорошее соответствие аппроксимации (6) результатам плосковолновых экспериментов [8] при предложенном способе определения констант сжимаемости начальной свободной пористости.

\section{2. Ударная адиабата водонасыщенного грунта}

Для определения параметров ударной адиабаты (1) водосодержащего уплотненного грунта применим подход разд. 2.1 к результатам обращенных экспериментов, так как результатов плосковолновых экспериментов для грунтов с плотностью более $1600 \mathrm{~kg} / \mathrm{m}^{3}$ получено недостаточно. В работе [19] получены зависимости максимальной силы сопротивления от скорости удара $F\left(V_{0}\right)$ при взаимодействии песчаного грунта средней плотности $\rho_{0}=1725 \mathrm{~kg} / \mathrm{m}^{3}$ и $w=0.1 \%$ с цилиндрическим стержнем с плоским передним торцом, определены константы ударной адиабаты (1) $A=455 \mathrm{~m} / \mathrm{s}, b=2.25$ [19].

При значениях параметров трехкомпонентной смеси $\alpha_{1}=0.3486, \alpha_{2}=0.001, \alpha_{3}=0.6504$, начальной плотности $\rho_{0}=1730 \mathrm{~kg} / \mathrm{m}^{3}$ и влажности грунта $w=0.1 \%$ определены значения констант уравнения (6), отвечающих пористому компоненту, которые составили $B_{1}=103 \mathrm{MPa}$ и $n_{1}=1.4$. Для грунта с влажностью $w=18 \%$ и начальной плотностью $\rho_{0}=2035 \mathrm{~kg} / \mathrm{m}^{3}$ получены значения параметров уравнения (6): $\alpha_{1}=0.0396$, $\alpha_{2}=0.31, \alpha_{3}=0.6504$.

На рис. 7 представлены ударные адиабаты песчаной смеси с размерами частиц $0.1-1.0 \mathrm{~mm}$ начальной плотности $1730 \mathrm{~kg} / \mathrm{m}^{3}$ : светлые кружки, треугольники и квадраты соответствуют данным обращенных экспериментов [19], полученным при влажности $w=0.1$, 10 и 18\% соответственно; аналогично темные кружки, треугольники и квадрат соответствуют данным плосковолновых экспериментов [9], сплошная, штриховая и 


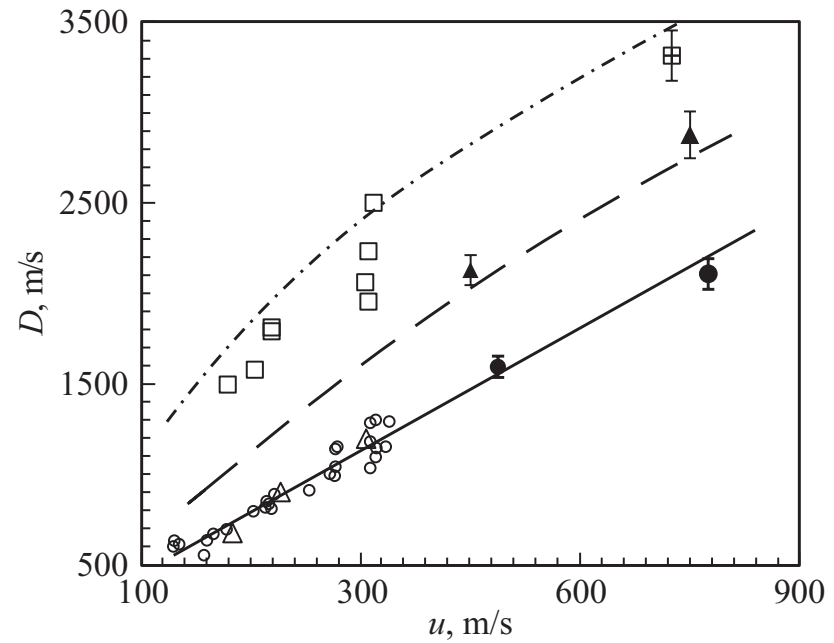

Pис. 7. Ударные адиабаты песка начальной плотности $1730 \mathrm{~kg} / \mathrm{m}^{3}$ и влажности $0.1,10$ и $18 \%$, полученные в результате обращенных экспериментов [19] (светлые маркеры), плосковолновых экспериментов [9] (темные маркеры) и по модели трехкомпонентной среды (6) (линии).

Таблица 2. Константы ударной адиабаты $D(u)$ для песка различной влажности

\begin{tabular}{c|c|c|c|c}
\hline № & $w, \%$ & $\rho_{0}, \mathrm{~kg} / \mathrm{m}^{3}$ & $A, \mathrm{~m} / \mathrm{s}$ & $b$ \\
\hline 1 & 0.1 & 1725 & 455 & 2.25 \\
2 & 10 & 1895 & 645 & 3.2 \\
3 & 18 & 2035 & 1290 & 3.6 \\
4 & 20 & 2075 & 1700 & 3.5
\end{tabular}

штрихпунктирная линии получены по формуле (6) в рамках модели трехкомпонентной среды.

Из рис. 7 видно, что ударные адиабаты сухого песка, полученные на основе экспериментальных данных $[9,19]$ и в рамках модели трехкомпонентной среды (6), хорошо совпадают друг с другом при сохранении линейной зависимости $D(u)$ в диапазоне скоростей $50-750 \mathrm{~m} / \mathrm{s}$. Для практически полностью водонасышенного песка (степень водонасыщения 90\%) также наблюдается соответствие модели (6) и экспериментальных данных $[9,19]$, при этом зависимость $D(u)$ имеет нелинейный характер. Ударная адиабата $D(u)$ для песка влажности 10\% (степень водонасыщения 50\%) при массовых скоростях до $300 \mathrm{~m} / \mathrm{s}$ практически совпадает с ударной адиабатой сухого песка [19], что отличается от предсказываемых по модели (6). При скоростях, не превышающих $750 \mathrm{~m} / \mathrm{s}$, наблюдается соответствие данных модели трехкомпонентной среды и эксперимента [9].

Таким образом, показана применимость модели трехкомпонентной среды (6) к описанию ударной адиабаты грунта при отсутствии влаги и при состоянии, близком к полному водонасыщению грунта, что также подтверждает достоверность оценки ударной адиабаты по формулам (3)-(5).
Константы ударной адиабаты (1) на основе уравнения (6) модели трехкомпонентной среды, полученные при изменении массовой скорости $u$ в диапазоне от 50 до $350 \mathrm{~m} / \mathrm{s}$ для песка различной влажности, сведены в табл. 2.

\section{3. Сопротивление сдвигу водонасыщенного песка}

Ранее проводился расчетно-экспериментальный анализ чувствительности силы сопротивления внедрению в сухой песок к изменению параметров модели мягкой грунтовой среды [17]. Было показано, что результаты экспериментов с применением цилиндрических ударников с плоским торцом, для которых различие между силами сопротивления на начальной и квазистационарной стадиях максимально, могут успешно применяться для идентификации сдвиговых характеристик грунтовой среды [17]. Был построен сходящийся итерационный процесс уточнения текущих значений материальных функций в образце путем минимизации рассогласования расчетных и экспериментальных данных в ходе выполнения серии вычислительных экспериментов. На основании результатов обращенных экспериментов по прониканию в сухой песчаный грунт ударников с плоскими и полусферическими оголовками при скоростях удара $50-450 \mathrm{~m} / \mathrm{s}$ были определены параметры ударной адиабаты [19] и зависимости предела текучести от давления [20], значения которых близки к значениям, полученным по результатам испытаний песка в обойме $[11,15]$.

В настоящей работе экспериментально-расчетный метод [17] был применен и для определения параметров зависимости предела текучести от давления, характеризующей сопротивление сдвигу водонасыщенного песка. Грунт описывается в рамках модели упругопластической грунтовой среды $[3,4]$, выражающей законы сохранения массы, импульса. Сдвиговое деформирование описывалось уравнениями теории пластического течения. Уравнения записывались в цилиндрической системе координат в дифференциальной форме. Система дифференциальных уравнений в частных производных замыкается конечными соотношениями [20-22], определяющими динамическую сжимаемость и сопротивление сдвигу грунтовой среды. Поверхностное трение в численных расчетах не учитывалось, так как смещения частиц грунта вдоль плоского торца стержня-ударника практически отсутствуют, а обтекание грунтовым потоком примыкающей к торцу цилиндрической части носит кавитационный характер.

Сопротивление сдвигу можно описать дробно-рациональной зависимостью предела текучести грунта от давления $\sigma(p)=k p /(1+k p / Y)$, где $k-$ коэффициент внутреннего трения, $Y$ - максимальное значение предела текучести; величиной сцепления для данного типа грунта можно пренебречь. Необходимая в расчете зависимость давления от объемной деформации (плот- 


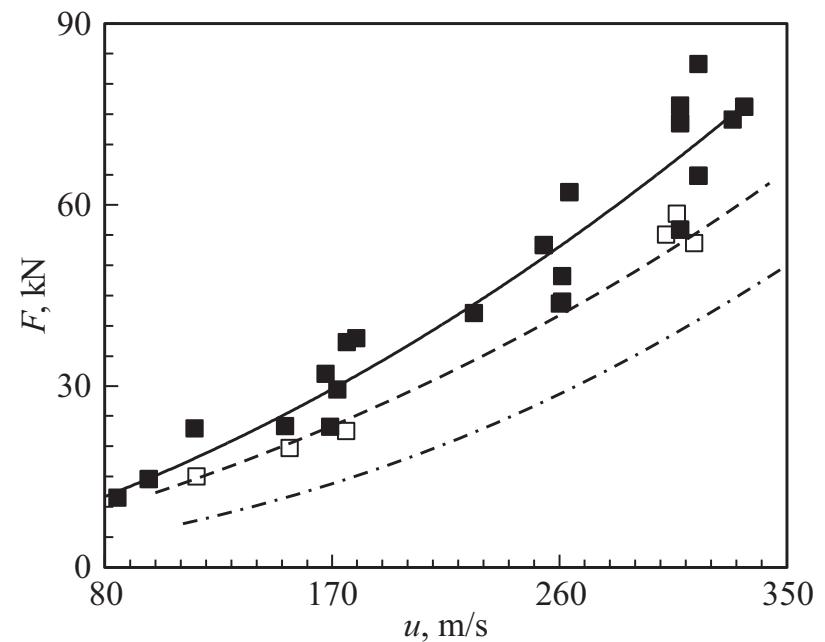

Рис. 8. Значения силы сопротивления внедрению в сухой и водонасыщенный песчаный грунт ударника с плоским торцом оголовком на квазистационарной стадии внедрения (эксперимент и численный расчет).

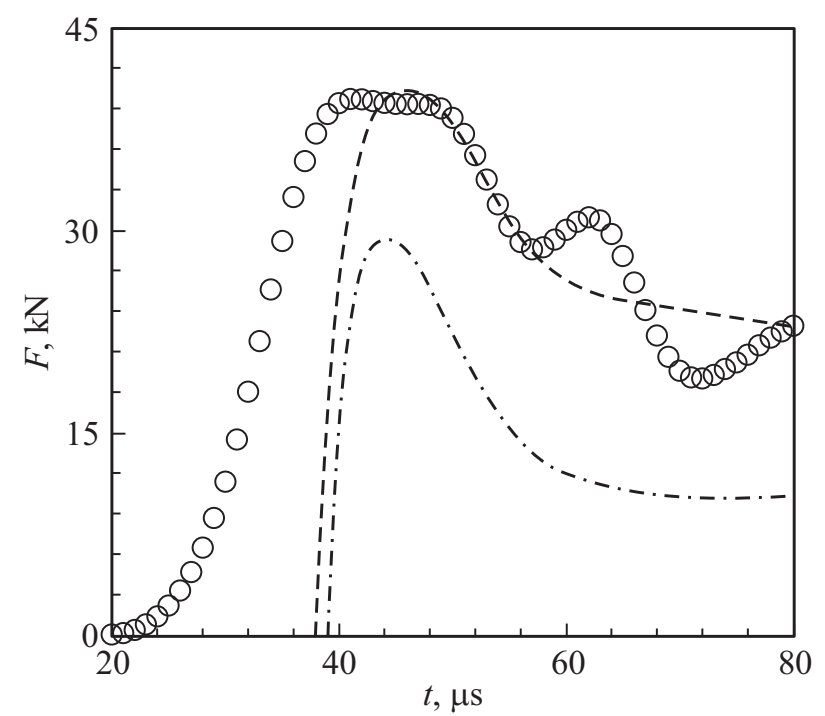

Рис. 9. Зависимость силы сопротивления внедрению в водонасыщенный песчаный грунт ударника с полусферическим оголовком со скоростью $282 \mathrm{~m} / \mathrm{s}$ (эксперимент и численный расчет).

ности) принимается в виде $p(\theta)=\rho_{0} a^{2} \theta /(1-b \theta)^{2}$, где $a=A / \sqrt{1+2 k / 3}[15]$.

По результатам серии расчетов получены следующие значения параметров уравнения состояния водонасыщенного песка: $A=1300 \mathrm{~m} / \mathrm{s}, b=3.6, k=0.5$, $Y=50 \mathrm{MPa}$. Для сухого песка ранее были получены: $A=455 \mathrm{~m} / \mathrm{s}, b=2.25, k=1.2$ и $Y=300 \mathrm{MPa}$ [19].

Ниже приведены результаты численных расчетов проникания в водонасыщенный песчаный грунт цилиндрического ударника с плоским передним торцом в упругопластической постановке. Для сравнения приведены результаты расчетов в гидродинамической постановке, когда грунт описывается моделью нелинейной сжимаемой жидкости с той же ударной адиабатой, но при полном отсутствии сопротивления сдвигу $(k=Y=0$, $a=A)$.

На рис. 8 представлены значения силы сопротивления в сухой и водонасыщенный песок на квазистационарной стадии внедрения в зависимости от массовой скорости $u$. Светлыми и темными квадратами показаны результаты обращенных экспериментов с применением сухого и водонасыщенного песка соответственно, сплошная и штриховая линии соответствуют результатам численных расчетов по внедрению ударника в сухой и водонасыщенный песок (строки 1 и 3 табл. 2); штрихпунктирной линией обозначены результаты расчетов в гидродинамической постановке (параметры ударной адиабаты представлены в строке 4 табл. 2).

На рис. 9 приведены зависимости от времени силы сопротивления внедрению ударника с полусферическим оголовком в водонасыщенный песчаный грунт со скоростью $V_{0}=282 \mathrm{~m} / \mathrm{s}$. Светлые точки соответствуют результатам обращенного эксперимента, штриховой и штрихпунктирной линиями обозначены результаты численных расчетов соответственно, при учете сдвиговых свойств и без их учета, т.е. в гидродинамической постановке.

Из рис. 8 и 9 видно, что квазистационарные значения сил сопротивления внедрению ударников с плоским передним торцом и полусферическим оголовком в грунт, полученные в экспериментах, близки к расчетным значениям при учете сдвиговых свойств в рамках модели сжимаемой упругопластической среды. Результаты расчетов в гидродинамической постановке существенно отличаются от экспериментальных данных.

Таким образом, при практически полном водонасыщении уплотненного песка его сдвиговые свойства снижаются, однако они остаются существенными и их необходимо учитывать. Полученные результаты будут полезны при анализе нагрузок, действующих на головные части твердых деформируемых тел, проникающих в водосодержащие грунты.

\section{Заключение}

Представлены новые результаты динамических испытаний по ударному сжатию уплотненного водонасыщенного песчаного грунта в обращенной постановке. На основании расчетно-экспериментального анализа зависимостей максимальных значений силы сопротивления внедрению от скорости удара определена ударная сжимаемость грунта; получены квазистационарные значения силы сопротивления, которые использовались для определения сопротивления сдвигу в рамках модели сжимаемой упругопластической среды. Показано, что необходимо учитывать сдвиговые свойства уплотненного водонасыщенного грунта в численных расчетах процессов проникания ударников с цилиндрическими и полусферическими оголовками в грунт. Модель грунта 
с применением гидродинамического приближения приводит к большим погрешностям в вычислении силы сопротивления внедрению.

Проведена верификация модели трехкомпонентной среды для аппроксимации ударной адиабаты сухого и водонасыщенного грунта на основе известных данных плосковолнового эксперимента для песка малой плотности и полученных в настоящей работе результатов обращенного эксперимента для уплотненного песка. Показана применимость модели к описанию ударной адиабаты грунта как при отсутствии влаги, так и при состоянии, близком к полному водонасыщению грунта.

В то же время при малом содержании влаги модель взаимопроникающих сред (6) может оказаться неприменимой в силу малого размера частиц жидкости [39]. Ударная адиабата песка влажностью $w=10 \%$, полученная в обращенных экспериментах с применением цилиндрического ударника с плоским передним торцом в диапазоне скоростей $100-350 \mathrm{~m} / \mathrm{s}$, оказывается близка к ударной адиабате сухого песка [19] с погрешностью, не превышающей разброс экспериментальных данных. Параметры ударных адиабат, полученные в рамках модели (6) при $w=0.1$ и 10\%, приведены в строках 1 и 2 табл. 2 и отличаются друг от друга в 1.5 раза. Известны также экспериментальные результаты [44], демонстрирующие близость максимальных значений сил сопротивления внедрению ударника с полусферическим оголовком в уплотненный песчаный грунт при влажности $w=0.1$ и $10 \%$. Это свидетельствует о сравнимых величинах сопротивления сдвигу в этих грунтах [45]. Таким образом, зависимость параметров ударной адиабаты от влажности при малом и/или неполном водонасыщении требует дальнейшего исследования.

Работа выполнена при финансировании РФФИ (проекты №№ 16-08-00825, 15-08-07977, 16-01-00524) и гранта № 9.6109.2017/6.7 Госзадания Минобрнауки РФ.

\section{Список литературы}

[1] Лагунов В.А., Степанов В.А. // ПМТФ. 1963. № 1. С. 88 96.

[2] Баллистические установки и их применение в экспериментальных исследованиях / Под ред. Н.А. Златина, Г.И. Мишина. М.: Наука, 1974. 344 с.

[3] Григорян С.С. // ПММ. 1960. Т. 24. № 6. С. 1057-1072.

[4] Григорян С.С. // ПМТФ. 1962. № 2. С. 1280-130.

[5] Ляхов Г.М. // ПМТФ. 1963. № 1. С. 121-124.

[6] Omidvar M., Iskander M., Bless S. // Int. J. Imp. Eng. 2012. Vol. 49. P. 192-213.

[7] Дианов М.Д., Златин Н.А., Мочалов С.М. и др. // Письма в ЖТФ. 1976. Т. 2. Вып. 12. С. 529-532.

[8] Брагов А.М., Грушевский Г.М. // Письма в ЖТФ. 1993. Т. 19. Вып. 12. С. 70-72.

[9] Arlery M., Gardou M., Fleureau J.M., Mariotti C. // Intern. J. Impact Engineer. 2010. Vol. 37. P. 1-10.

[10] Bragov A.M., Grushevsky G.M., Lomunov A.K. // Exper. Mech. 1996. Vol. 36. N 3. P. 237-242.
[11] Брагов А.М., Котов В.Л., Ломунов А.К., Сергеичев И.В. // Изв. СО РАН. ПМТФ. 2004. Т. 45. № 4. С. 147-153.

[12] Song B., Chen W., Luk V. // Mechan. Mater. 2009. Vol. 41. P. 777-785.

[13] Martin B.E., Chen W., Song B., Akers S.A. // Mechan. Mater. 2009. Vol. 41. P. 786-798.

[14] Брагов А.М., Ломунов А.К., Сергеччев И.В. и др. // Письма в ЖТФ. 2005. Т. 31. Вып. 12. С. 83-87.

[15] Баландин В.В., Брагов А.М., Игумнов Л.А., Котов В.Л., Ломунов А.К., Константинов А.Ю. // Изв. РАН. МТТ. 2015. № 3. C. 69-77.

[16] Бивин Ю.К. // МТТ. 2008. № 1. С. 154-160.

[17] Бажсенов В.Г., Котов В.Л. // ДАН. 2006. Т. 408. № 3. C. 333-336.

[18] Баландин В.В., Брагов А.М. // ПППП. Методы решения: Межвуз. сб. Н. Новгород: Изд-во ННГУ, 1991. С. 101-104.

[19] Брагов А.М., Баландин В.В., Ломунов А.К., Филиппов А.Р. // Письма в ЖТФ. 2006. Т. 32. Вып. 11. С. 52-55.

[20] Бажсенов В.Г., Брагов А.М., Котов В.Л. // ПМТФ. 2009. T. 50. № 6. C. 115-125.

[21] Котов В.Л., Баландин В.В., Брагов А.М., Баландин В.В. // ДАН. 2013. Т. 451. № 3. С. 278-282.

[22] Брагов А.М., Баландин В.В., Баландин В.В., Котов В.Л. // ЖТФ. 2016. Т. 86. Вып. 6. С. 62-70.

[23] Баландин В.В., Котов В.Л. // Проблемы прочности и пластичности. 2016. Т. 78. № 4. С. 388-395.

[24] Котов В.Л., Баландин Вл.В., Баландин Вл.Вл. // Вестник ПНИПУ. Механика. 2016. № 3. С. 97-107.

[25] Кольский Г. Волны напряжения в твердых телах. М.: ИЛ, 1955. $194 \mathrm{c}$.

[26] Дейвис P.М. Волны напряжений в твердых телах. М.: ИЛ, 1961. $104 \mathrm{c}$.

[27] Корнев В.М. // ПМТФ. 1992. № 3. С. 127-131.

[28] Юношев А.С., Сильвестров В.В. // ПМТФ. 2001. Т. 42. № 3. C. 212-220.

[29] Bacon C., Lataillade J.-L. Development of the KolskyHopkinson technics and applications for non-conventional testing / In New experimental methods in material dynamics and impact. Nowacki W.K., Klepaczko J.R. (Eds). 2001. Warsaw. Poland. P. 1-58.

[30] Gary G. Some aspects of dynamic testing with wave-guides / In New experimental methods in material dynamics and impact. Nowacki W.K., Klepaczko J.R. (Eds). 2001. Warsaw. Poland. P. 179-222.

[31] Брагов А.М., Константинов А.Ю., Медведкина М.В. // Вестник Нижегородского ун-та им. Н.И. Лобачевского. 2011. № 6 (1). C. 158-162.

[32] Follansbee P.S., Frantz C. // J. Engineer. Mater. Technol. 1983. Vol. 105. N 1. P. 61-66. doi:10.1115/1.3225620.

[33] Gorham D. // J. Phys. E: Scientific Instruments. 1983. Vol. 16. P. 477-479. doi:10.1088/0022-3735/16/6/008.

[34] Tyas A, Pope D.J. // Measurement Sci. Technol. 2005. Vol. 16. N 3. P. 642-652. doi:10.1088/0957-0233/16/3/004.

[35] Tyas A., Watson A.J. // Measurement Sci. Technol. 2000. Vol. 11. P. 1539-1551.

[36] Merle R., Zhao H. // Intern. J. Impact Engineer. 2006. Vol. 32. N 12. P. $1964-1980$.

[37] Tyas A., Ozdemir Z. // Philosophical Transactions of the Royal Society A: Mathematical, Physical and Engineering Sciences. 2014. Vol. 37. N 2. P. 1-11. doi: 10.1098/rsta.2013.0291.

[38] Котов В.Л., Брагов А.М., Баландин Вл.В., Баландин Вл.Вл. // Письма в ЖТФ. 2017. Т. 43. Вып. 17. С. 64-70. 
[39] Дремин А.Н., Карпухин И.А. // ПМТФ. 1960. № 3. С. 184 188.

[40] Ляхов Г.М. Волны в грунтах и пористых многокомпонентных средах. М.: Наука, 1982. 288 с.

[41] Физика взрыва / Под ред. Л.П. Орленко. Изд. 3-е, испр. В 2-х т. Т. 1. М.: Физматлит, 2004. 832 с.

[42] Ададуров Г.А., Дремин А.Н., Першин С.В., Родионов В.Н., Рябинин Ю.Н. // ПМТФ. 1962. № 4. С. 81-89.

[43] Grujicica M., Pandurangan B., Qiao R., Cheeseman B.A., Roy W.N., Skaggs R.R., Gupta R. // Soil Dynam. Earthquake Engineer. 2008. Vol. 28. P. 20-35.

[44] Баландин В.В., Баландин В.В., Брагов А.М., Крылов С.В., Цветкова Е.В. // ПМТФ. 2015. Т. 56. № 6. С. 46-50.

[45] Баландин В.В., Зебиров С.В., Котов В.Л., Ломунов А.К., Трухин Б.В. // Вестник ННГУ. Серия Механика. 2004. Вып. 1 (6). С. 131-139. 